\title{
Intrinsic Antibacterial Borosilicate Glasses for Bone Tissue Engineering Applications
}

João S. Fernandes, ${ }^{*},{ }^{\dagger} \neq$ Margarida Martins, ${ }^{\dagger \neq}$ Nuno M. Neves, ${ }^{\dagger, \ddagger}$ Maria H. V. Fernandes, ${ }^{\S}$ Rui L. Reis, ${ }^{\dagger,}$ and Ricardo A. Pires $*, \dagger$

\footnotetext{
${ }^{\dagger}$ 3B’s Research Group - Biomaterials, Biodegradables and Biomimetics, University of Minho, Headquarters of the European Institute of Excellence on Tissue Engineering and Regenerative Medicine, AvePark-Parque de Ciência e Tecnologia, Zona Industrial da Gandra, 4805-017 Barco GMR, Portugal

${ }^{\ddagger}$ ICVS/3B’s - PT Government Associate Laboratory, Braga/Guimarães, 4710-057 Portugal

${ }^{\S}$ Materials and Ceramic Engineering Department, CICECO - Aveiro Institute of Materials, University of Aveiro, 3810-193 Aveiro, Portugal
}

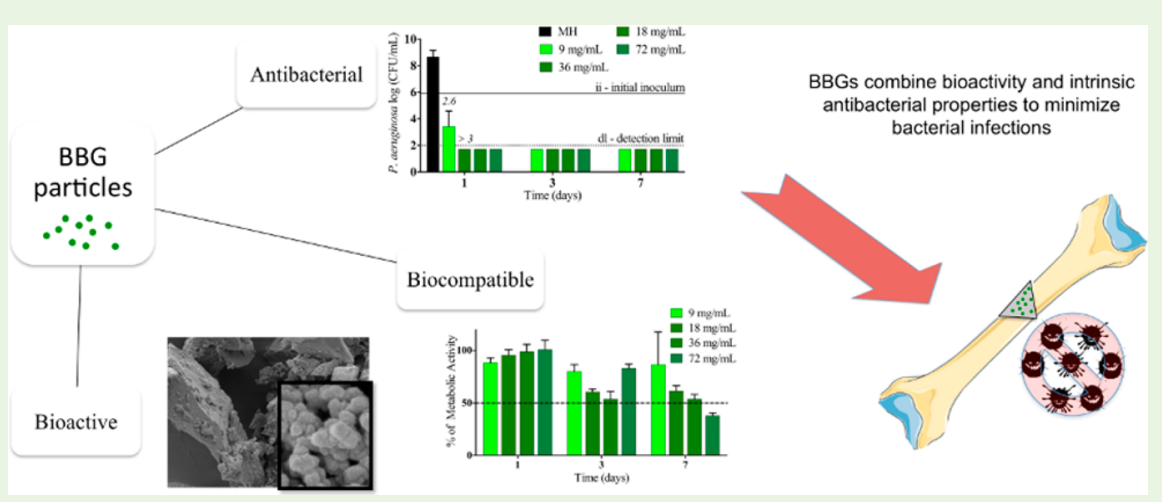

ABSTRACT: Three novel borosilicate bioactive glasses (BBGs) were prepared and used to investigate their bioactive and antibacterial properties. The BBGs were prepared by melt-quenching using different glass modifiers, i.e. $\mathrm{Mg}^{2+}, \mathrm{Ca}^{2+}$, and $\mathrm{Sr}^{2+}$, and their amorphous nature was confirmed by X-ray diffraction. Scanning electron microscopy with energy dispersive X-ray spectroscopy allowed the visualization of apatite-like structures upon 7 days of immersion in simulated body fluid. BBG-Ca generated surface structures with a $\mathrm{Ca} / \mathrm{P}$ ratio $\approx 1.67$, while the surface of the BBG-Sr was populated with structures with a $\mathrm{Sr} / \mathrm{P}$ ratio $\approx 1.7$. Moreover, bacterial tests showed that the BBG-Mg and BBG-Sr glasses (at concentrations of 9, 18, 36, and 72 mg/ $\mathrm{mL}$ ) present antibacterial characteristics. In particular, BBG-Sr, at concentrations of $9 \mathrm{mg} / \mathrm{mL}$, exhibited bacteriostatic activity against Pseudomonas aeruginosa, and at concentrations $\geq 18 \mathrm{mg} / \mathrm{mL}$ it was able to eradicate this bacterium. These results evidence an antibacterial activity dependent on the BBGs composition, concentration, and bacterial species. Cellular studies showed that the developed BBGs do not present a statistically significant cytotoxic effect against Saos- 2 cells after 3 days of culture, showing better performance (in the cases of BBG-Ca and BBG-Sr) than commercial 45S5 Bioglass up to 7 days of culture. Overall, this study demonstrates that BBGs can be effectively designed to combine bioactivity and intrinsic antibacterial activity targeting bone tissue engineering applications.

KEYWORDS: borosilicate bioactive glasses, glass modifiers, Sr-containing glasses, Mg-containing glasses, antibacterial activity

\section{INTRODUCTION}

In recent years, tissue engineering has shown great promise for the repair, replacement, and even regeneration of bone defects. A large diversity of bioactive glasses (BGs) has been reported. Usually they present enhanced capacity to interact with bone due to their capability to form a hydroxyapatite layer (HA) under simulated physiological conditions. ${ }^{1}$ The $\mathrm{CaO}$ :$\mathrm{SiO}_{2}: \mathrm{Na}_{2} \mathrm{O}: \mathrm{P}_{2} \mathrm{O}_{5}$ system (45S5 Bioglass) ${ }^{1}$ has been the gold standard for BGs, but it has limitations, namely related with its degradation rates. When transformed into glass ceramics, these silica based BGs have slow degradation rates, after being implanted, which makes it difficult to match with the rate of new tissue formation. ${ }^{2,3}$ The conversion of the BGs to a bone- like HA is slow and often incomplete. ${ }^{2}$ Moreover, the huge increase in joint and bone implant surgeries is usually accompanied by an increase in the incidence of implant-related bacterial infections. This can lead to the failure of the implant-a growing public health concern in developed countries. $^{4,5}$

A broad spectrum of bacterial species can be found at implant sites, including Pseudomonas aeruginosa, Escherichia coli, Staphylococcus aureus, and Staphylococcus epidermidis. These

Received: March 22, 2016

Accepted: June 16, 2016

Published: June 16, 2016 
species have been associated with joint and bone infections. ${ }^{4,6}$ As an example, $P$. aeruginosa and $S$. aureus were reported by Malizos et al. ${ }^{7}$ to be related with ankle and foot osteomyelitis after surgical treatment. Consequently, it is becoming urgent to develop double-edged materials capable of perfect bonds to bone and that exhibit intrinsic antibacterial activity.

The borosilicate bioactive glasses (BBGs) have been gaining interest due to the possibility to easily control their degradation rates and due to their strong bioactivity. ${ }^{8,9}$ The compositional flexibility of these glasses is high and can be tailored to improve $\mathrm{BBGs}$ osteogenic and angiogenic properties by the addition of specific glass modifiers. ${ }^{10,11}$ On one hand, network formers such as silicon and boron are well-known to stimulate bone formation and precipitation of HA. Silicon is known to be essential for different processes, such as bone formation and calcification. ${ }^{12,13}$ In addition, boron is related with the improved adhesion of bone cells and bone resistance to fracture. ${ }^{14}$ On the other hand, the therapeutic cations, such as $\mathrm{Mg}^{2+15,16} \mathrm{Ca}^{2+}$, ${ }^{17}$ and $\mathrm{Sr}^{2+18,19}$ are involved in cells adhesion and stability; apatite formation process and cell differentiation; and bone formation and mineralization, respectively. In fact, $\mathrm{Sr}^{2+}$ has been reported for the treatment of osteoporosis. ${ }^{20}$

Furthermore, several cations can provide antibacterial properties to BGs. Specifically, silver, ${ }^{21}$ copper, $^{22}$ and cerium ${ }^{23}$ can provide bacteriostatic and/or bactericidal properties to BGs. Remarkably, other cations may also provide antibacterial properties to BGs, as previously shown for $\mathrm{Mg}^{2+},{ }^{24} \mathrm{Ca}^{2+}$, and $\mathrm{Sr}^{2+} \cdot{ }^{25,26}$ In this context, the incorporation of different cations can impart a series of therapeutic features into BGs, and their properties can be suited to meet the clinical needs.

Therefore, the main objective of this work is 2-fold: (1) to develop three novel melt-quench BBGs, prepared with the glass modifiers $\mathrm{Ca}^{2+}, \mathrm{Sr}^{2+}$, or $\mathrm{Mg}^{2+}$, that are able to present enhanced bioactivity; (2) to investigate their intrinsic antibacterial properties. We aimed to contribute to the development of $\mathrm{BBGs}$ that couple bone regenerative properties with intrinsic antibacterial activity relevant in the bone tissue engineering context.

\section{MATERIALS AND METHODS}

2.1. Glasses' fabrication. $\mathrm{BBGs}$ of general formula $0.05 \mathrm{Na}_{2} \mathrm{O}$. $x \mathrm{MgO} \cdot y \mathrm{CaO} \cdot(0.35-x-y) \mathrm{SrO} \cdot 0.20 \mathrm{~B}_{2} \mathrm{O}_{3} \cdot 0.40 \mathrm{SiO}_{2}$ (molar ratio, where $x$, $y=0.35$ or 0.00 , and $x \neq y$ ) were fabricated by melt-quenching. The appropriate amounts of diboron trioxide $\left(\mathrm{B}_{2} \mathrm{O}_{3}\right.$, Alfa Aesar, Germany), sodium bicarbonate $\left(\mathrm{NaHCO}_{3}\right.$, Sigma-Aldrich, Australia), silica gel 60 $\mathrm{M}\left(\mathrm{SiO}_{2}\right.$, Macherey-Nagel, Germany), and magnesium oxide ( $\mathrm{MgO}$, Sigma-Aldrich, Portugal $)$ or calcium carbonate $\left(\mathrm{CaCO}_{3}\right.$, SigmaAldrich, Portugal), or strontium carbonate $\left(\mathrm{SrCO}_{3}\right.$, Sigma-Aldrich, Portugal) were thoroughly mixed with addition of ethanol in a porcelain mortar with the help of a pestle, dried overnight, and transferred to a platinum crucible. Afterward, the batch was heated to $1450{ }^{\circ} \mathrm{C}$ in air for $1 \mathrm{~h}$, and subsequently the melt was quickly poured into cold water for a fast cooling step, forming a glass frit with no crystalline phases. Afterward, pieces of the as-quenched glass were quickly removed from water, dried to remove all the nonstructural water, and ground in an Agate mortar (RETSCH, Germany). After overnight vacuum drying, the glasses were sieved to a particle size lower than $63 \mu \mathrm{m}$. Before the in vitro tests, the BBG-Mg, BBG-Ca, and BBG-Sr were weighted and sterilized by ethylene oxide (the sterilizing gas was composed by $88 \% \mathrm{CO}_{2}$ and $12 \%$ ethylene oxide using the following physical parameters: temperature of $45^{\circ} \mathrm{C} \pm 3{ }^{\circ} \mathrm{C}$; pressure of $180+3 \mathrm{kPa}$; humidity of $55 \pm 10 \% \mathrm{HR}$; and exposure time of 10 h).

2.2. Glasses' characterization. 2.2.1. Morphology and density. Scanning electron microscopy (SEM) was used to observe the morphology of the BBGs particles. Prior to the analysis, all BBGs samples were sputter-coated with gold (sputter coater model SC502, Fisons Instruments, England). All the micrographs were acquired on a Leica Cambridge S360 microscope (Leica Cambridge, England) using beam energy of $5.0 \mathrm{kV}$ and working distance of $\approx 5.2 \mathrm{~mm}$.

The BBGs density was determined using a multi pycnometer (Quantachrome Instruments, USA). Measurements were performed with helium at $110^{\circ} \mathrm{C}$ using $\approx 5 \mathrm{~g}$ of each sample.

2.2.2. Crystallinity. X-ray powder diffraction (XRD) was used to confirm the amorphous state of BBGs. The BBGs diffractograms were collected on a Bruker D8 Discover (Germany), operating with a $\mathrm{Cu}$ $\mathrm{K} \alpha$ radiation $\theta / 2 \theta$ mode between $10^{\circ}$ and $60^{\circ}$, with a step increment of $0.04^{\circ}$ and an acquisition time of 1 s per step.

2.2.3. Elemental composition. Inductively coupled plasma atomic emission spectrometry (ICP-AES - Horiba, Japan) was used to determine the elemental composition of the glasses $(\mathrm{B}, \mathrm{Si}, \mathrm{Na}, \mathrm{Ca}, \mathrm{Sr}$, and $\mathrm{Mg}$ ) after total dissolution of $1 \mathrm{~g}$ of each BBG into hydrofluoric acid. The sample absorption was measured at specific wavelengths $(\lambda=$ 588.995 for $\mathrm{Na}, \lambda=279.553 \mathrm{~nm}$ for $\mathrm{Mg}, \lambda=393.366 \mathrm{~nm}$ for $\mathrm{Ca}, \lambda=$ $588.995 \mathrm{~nm}$ for $\mathrm{Sr}, \lambda=249.773 \mathrm{~nm}$ for $\mathrm{B}$, and $\lambda=251.611 \mathrm{~nm}$ for $\mathrm{Si}$ ), and their concentration was determined using calibration curves obtained with standard solutions (VWR, Portugal) in the range from 5 $\times 10^{3}$ to $10 \mathrm{ppm}$.

2.3. Bioactivity of the glasses. Simulated body fluid (SBF) was produced in accordance with the procedure described by Kokubo et al. ${ }^{27}$ Triplicate samples of the prepared BBGs, with a particle size lower than $63 \mu \mathrm{m}$, were immersed in SBF at a ratio of 10:15 [BBG $(\mathrm{mg})$ : SBF $(\mathrm{mL})]$ and incubated for 1,3 , and 7 days in an oven maintained at $37^{\circ} \mathrm{C}$. After each time point BBGs were recovered and dried at $37^{\circ} \mathrm{C}$. The gold or carbon sputter coated samples were analyzed by SEM (model S360, Leica Cambridge, England) equipped with energy dispersive X-ray spectroscopy (SEM/EDS link-eXL-II) for morphological and chemical analysis.

2.4. Degradation of the glasses. Samples of the fabricated BBGs were immersed in the bacterial growth medium Muller Hinton (MH) (at least in triplicate) at concentrations of $9,18,36$, and $72 \mathrm{mg} / \mathrm{mL}$ for 1,3 , and 7 days and maintained at $37^{\circ} \mathrm{C}$ in a water-shaking bath at 60 $\mathrm{rpm}$. At each time point, the solutions were filtered and the $\mathrm{pH}$ was assessed. The ICP-AES analyses were performed as described in section 2.2.3 to determine the concentrations of $\mathrm{Si}, \mathrm{B}, \mathrm{Mg}, \mathrm{Ca}$, and $\mathrm{Sr}$ released by the BBGs in $\mathrm{MH}$.

2.5. Antibacterial properties. The standard disc diffusion (DD) (2.5.1) and the broth dilution (BD) (2.5.2) assays ${ }^{28,29}$ were adapted to test the ability of the BBGs to act against the Gram-negative bacteria $P$. aeruginosa (American Type Culture Collection, ATCC 27853) and E. coli (Colección Española de Cultivos Tipo, CECT 434); and the Gram-positive S. aureus (ATCC 25913) and S. epidermidis (strain $9142^{30}$ ). These bacterial strains were chosen to represent a spectrum of organisms associated with joint and bone infections. ${ }^{4}$ For these experiments, different concentrations $[9,18,36,72 \mathrm{mg} / \mathrm{disc}$ (DD) or/ $\mathrm{mL}(\mathrm{BD})]$ of each BBGs were used. Additionally, 45S5 Bioglass (NOVABONE, USA) was used as commercial control; and culture medium without BBGs was used as a negative control. The antibacterial properties of $\mathrm{BBGs}$ as a function of the culture time were investigated by $\mathrm{BD}$ assays for those glasses that exhibited antibacterial activity on DD. All experiments were performed at least in triplicate and repeated three times independently.

2.5.1. Disc diffusion assay. For the DD assay, ${ }^{28}$ agar discs $(17 \mathrm{~g} / \mathrm{L}$ (Liofilchem, Portugal), $\varnothing \approx 9.5 \mathrm{~mm}$ ) were charged with different concentrations of BBGs and used on the same day.

The direct colony suspension method was used to prepare a saline suspension of each microbial species previously grown in Tryptone Soya Agar (TSA, Liofilchem, Portugal) at $37^{\circ} \mathrm{C}$ for $18 \mathrm{~h}$. The density of the suspensions was adjusted to that of a McFarland 0.5 turbidity standard, corresponding to approximately $1-2 \times 10^{8}$ colony forming unit $(\mathrm{CFU}) / \mathrm{mL}$. The inoculum concentration was confirmed by enumeration of CFU after culture of serial dilutions onto TSA and incubation at $37{ }^{\circ} \mathrm{C}, 18-24 \mathrm{~h}$ in air. The test was performed by applying the bacterial inoculum with a sterile cotton swab onto the surface of a $\mathrm{MH}$ agar (Liofilchem, Portugal) plate containing $25 \mathrm{~mL}$ of 


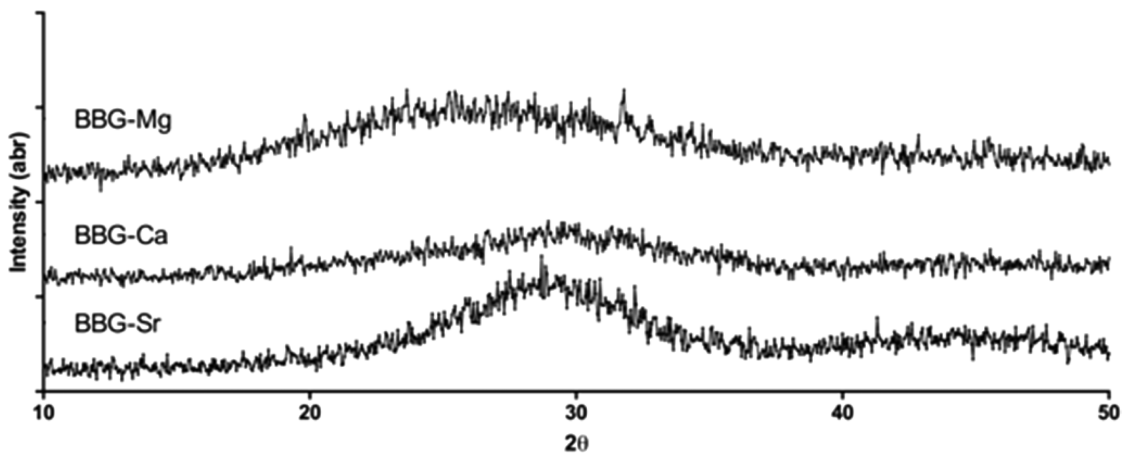

Figure 1. XRD patterns of the as-quenched glass frits, i.e. BBG-Mg, BBG-Ca, and BBG-Sr. Three replicates were performed for each sample, and representative spectra are presented.

medium. The glasses on agar discs were applied in the plates within 15 min of inoculation. The plates were incubated at $37^{\circ} \mathrm{C}$ in air for $18 \mathrm{~h}$ for all the bacteria. The diameter (in millimeters) of the inhibition zone around each disc was measured using a ruler. The presence of an inhibition halo was interpreted as bacterial susceptibility to the BBG.

2.5.2. Broth dilution assay. For the $\mathrm{BD}$ assay, ${ }^{29}$ the $\mathrm{BBGs}$ were immersed in $0.5 \mathrm{~mL}$ of $\mathrm{MH}$ (Fluka, Portugal) medium and incubated at $37^{\circ} \mathrm{C}$ in air for 0,2 , or 6 days.

For each bacterium, the inoculum was prepared as described for the DD test. It was diluted to approximately $1 \times 10^{6} \mathrm{CFU}$ in $0.5 \mathrm{~mL}$ of culture medium, added to the different tubes containing known amounts of BBGs dissolved during the specific time frames, and incubated at $37^{\circ} \mathrm{C}$ in air for $24 \mathrm{~h}$. Overall, the bacteria were tested for a fixed period after 1, 3, and 7 days of BBGs dissolution in $\mathrm{MH}$ medium. One sample was removed from each tube, serially diluted in saline, and inoculated onto TSA. After $24 \mathrm{~h}$ incubation at $37^{\circ} \mathrm{C}$ in air, the number of colonies were counted. The results are presented as $\log _{10} \mathrm{CFU} / \mathrm{mL}$. Bacteriostatic and bactericidal activities were defined as a reduction of bacteria less and more than $3 \log _{10} \mathrm{CFU} / \mathrm{mL}$, respectively, expressed as the proportion of the inoculum (number of living CFUs introduced in culture) that is rendered incapable of reproduction on subculture. ${ }^{31}$ Eradication was defined as the elimination of culturable bacteria upon subculture.

2.6. Cytotoxicity assay. The cytotoxicity assessment was performed by adapting the ISO 10993 5:2009 to the targeted bone tissue engineering application. The SaOs- 2 cells derived from human bone were cultured with BBGs at concentrations of 9, 18, 36, and 72 $\mathrm{mg} / \mathrm{mL}$ during 7 days. The cells cultured in the absence of glass particles were used as negative control, and in the presence of $45 \mathrm{S5}$ Bioglass as positive control. Cells were expanded in Dulbecco's Modified Eagle Medium (Sigma, Portugal) supplemented with 10\% heat-inactivated fetal bovine serum (Alfagene, Portugal) and $1 \%$ antibiotic/antimitotic solution $(100 \mathrm{U} / \mathrm{mL}$ penicillin and $100 \mu \mathrm{g} / \mathrm{mL}$ streptomycin; Alfagene, Portugal). Cells were cultured at $37^{\circ} \mathrm{C}$ in an atmosphere of $5 \% \mathrm{CO}_{2}$. Confluent SaOs-2 cells between passages 15 and 19 were harvested and seeded onto the bottom of 24-well plates at a density of $2.3 \times 10^{5}$ cells/well. The BBGs at the desired concentrations and 45S5 Bioglass were added on top, in cell culture inserts with porous membranes $(0.4 \mu \mathrm{m}$ ThinCerts Cell Culture Inserts; Greiner, Germany). The fabricated BBGs presented great biological performance without the common washing step before contact with cells. Therefore, cytotoxicity assay of samples and control (45S5 Bioglass) was performed without the common prewashing step.

The metabolic activity and cellular proliferation were monitored at 1, 3, and 7 days by MTS (3-(4,5-dimethylthiazol-2-yl)-5-(3carboxymethoxyphenyl)-2-(4-sulfophenyl)-2 H-tetrazolium - Promega, UK) and PicoGreen (Quant-iT PicoGreen dsDNA Assay Kit Invitrogen, USA), respectively, according to the supplier's instructions.

2.7. Statistical analysis. Experiments were run at least in triplicate for each sample. All the data were expressed as mean \pm standard deviation (SD). Statistical analysis was performed using Graphpad Prim software, version 6.0. The normality of the data distribution was monitored by Shapiro-Wilk test. Some of the data sets were not considered to have a normal distribution, requiring a nonparametric statistical evaluation. In this context, a Kruskal-Wallis test was applied to all data sets, followed by a Dunn's Multiple Comparison test. Values of $p<0.001$ were considered extremely significant, those of $0.001<p<$ 0.01 were considered very significant, and of those $0.01<p<0.05$ were considered significant.

\section{RESULTS AND DISCUSSION}

3.1. BBGs' fabrication and characterization. The BBGs network was designed to be a borosilicate (i.e., $0.2 \mathrm{~B}_{2} \mathrm{O}_{3}: 0.4 \mathrm{SiO}_{2}$ ) containing different network modifiers following the general formula $0.05 \mathrm{Na}_{2} \mathrm{O} \cdot x \mathrm{MgO} \cdot y \mathrm{CaO} \cdot(0.35-x-$ $y$ ) $\mathrm{SrO} \cdot 0.20 \mathrm{~B}_{2} \mathrm{O}_{3} \cdot 0.40 \mathrm{SiO}_{2}$ (molar ratio, where $x, y=0.35$ or 0.00 , and $x \neq y$ ). The BBGs were successfully obtained by meltquench and ground in a controlled manner. All the compositions presented a density ranging from 2.5 to $3.0 \mathrm{~g} /$ $\mathrm{cm}^{3}$. The increase of density was associated with the higher molecular weight of the glass modifier used to prepare the $\mathrm{BBG}$, i.e. $\mathrm{Mg}^{2+}<\mathrm{Ca}^{2+}<\mathrm{Sr}^{2+}$. Figure 1 presents the XRD data obtained for the three compositions, which confirm that the melting procedure and the fast quenching in water were an adequate strategy to obtain amorphous BBGs. In Figure 2

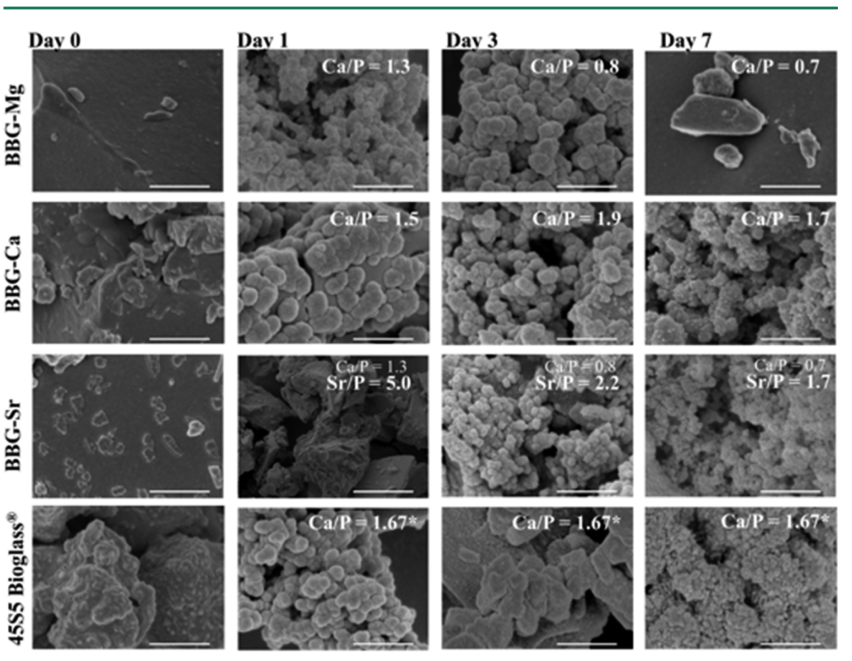

Figure 2. SEM micrographs of BBGs (BBG-Mg, BBG-Ca, and BBG$\mathrm{Sr}$ ) before and after 1, 3, and 7 days of immersion in SBF. Higher SEM magnifications are shown as insets highlighting the apatite-like structures. The 4555 Bioglass was used as a control. The $\mathrm{Ca} / \mathrm{P}$ or $\mathrm{Sr} / \mathrm{P}$ ratios on the surface of the BBGs were determined by EDS and presented on the right corner from day 1 to 7 . The asterisk (45S5 Bioglass) represents the theoretical value of the $45 \mathrm{~S} 5$ Bioglass $\mathrm{Ca} / \mathrm{P}$ ratio. Scale bar $=0.25 \mu \mathrm{m}$. 
Table 1. Elemental Composition of BBGs (BBG-Mg, BBG-Ca, and BBG-Sr) as Determined by ICP ${ }^{a}$

$\begin{array}{lcccc}\text { Sample } & \mathrm{Si}(\mathrm{mol} \mathrm{\%}) & \mathrm{B}(\mathrm{mol} \%) & \text { Divalent cation }{ }^{b}(\mathrm{~mol} \%) & \mathrm{Na}(\mathrm{mol} \%) \\ \text { BBG-Mg } & 37.2 \pm 0.2(40) & 17.0 \pm 0.1(20) & 40.6 \pm 0.1(35) & 4.9 \pm 0.1(5) \\ \text { BBG-Ca } & 33.7 \pm 0.3(40) & 21.0 \pm 0.1(20) & 37.9 \pm 0.3(35) & 7.3 \pm 0.1(5) \\ \text { BBG-Sr } & 34.8 \pm 0.3(40) & 21.0 \pm 0.1(20) & 38.9 \pm 0.3(35) & 5.1 \pm 0.1(5)\end{array}$

${ }^{a_{T}}$ The data was obtained from three replicates and is presented as the mean of $\%$ molar composition in $1 \mathrm{~g}$ of sample ( \pm standard deviation). Theoretical values are presented in parentheses. ${ }^{b}$ Varies with the different divalent cations for each composition: $\mathrm{Mg}^{2+}, \mathrm{Ca}^{2+}$, and $\mathrm{Sr}^{2+}$, from top to bottom.

(column t0) are presented the SEM images of BBGs after the grinding process. The BBGs exhibited an angular shape with low sphericity. The ICP-AES analysis (Table 1) confirmed the elemental composition of the BBGs, showing values close to the nominal theoretical composition.

3.2. BBGs in vitro bioactivity and degradation. The formation of bone-like apatite structures was assessed after the immersion of BBGs into the SBF buffer. Figure 2 presents the SEM images and $\mathrm{Ca} / \mathrm{P}$ ratios before and after 1,3 , and 7 days of immersion into SBF. The in vitro bioactivity assay revealed the presence of bone-like apatite structures onto the surface of all the BBGs, even though they are at different stages of crystallization.

The BBG-Mg particles exhibited the formation of bone-like apatite structures on their surface for days 1 and 3. However, there was a decrease of those structures at day 7. In fact, Salimi et al. ${ }^{32}$ showed that the $\mathrm{Mg}^{2+}$ has a marked inhibiting effect on $\mathrm{HA}$ growth due to its adsorption onto active growth sites. The BBG-Ca and 45S5 Bioglass presented a constant increase in the formation of bone-like apatite structures over time. Additionally, the structures observed at days 1, 3, and 7 of immersion presented the cauliflower-like morphology, typical of HA. Moreover, at day $7 \mathrm{BBG}-\mathrm{Ca}$ reached $\mathrm{Ca} / \mathrm{P} \approx 1.67$, which is commonly associated with HA. ${ }^{33}$ Finally, at day 7 the BBG-Sr glass also presented the formation of bone-like apatite structures onto the particles' surface with a cauliflower-like morphology. These structures were formed during a longer time period, and also they did not present the $\mathrm{Ca} / \mathrm{P}$ ratio expected for HA. However, the Sr/P ratio of BBG-Sr decreased over time, reaching $\approx 1.7$ at day 7 . This suggests the formation of strontium-substituted bone-like apatite (Sr-HA). ${ }^{34}$ Indeed, Ravi et al. ${ }^{35}$ supported the use of $\mathrm{Sr}^{2+}$ in the place of $\mathrm{Ca}^{2+}$ in HA structure forming synthetic Sr-HA. In fact, in the mechanism for the formation of apatite-like structures, proposed by Hench et al., ${ }^{36} \mathrm{Sr}^{2+}$ can replace $\mathrm{Ca}^{2+}$ and migrate to the surface of the $\mathrm{SiO}_{2}$-rich layer precipitated on the surface of BBGs, forming a $\mathrm{SrO}-\mathrm{P}_{2} \mathrm{O}_{5}$-rich film.

The BBG-Ca and BBG-Sr glasses have shown high capacity to form bone-like apatite structures at their surface with cation/ $\mathrm{P}$ ratio $\approx 1.67$ upon immersion in SBF, which might enable the glasses to establish direct contact with living bone cells. ${ }^{37}$

In order to better understand the kinetics of BBGs dissolution, a glass solubilization study was performed in $\mathrm{MH}$ medium (Figure 3). For BBG-Mg and BBG-Sr there was a fast initial glass dissolution up to day 3 and a subsequent slower increase over time. In contrast, the BBG-Ca presented a faster dissolution at day 1 followed by an increasing release over time. However, the amounts of $\mathrm{Mg}^{2+}$ in BBG-Mg and of $\mathrm{Sr}^{2+}$ in BBG$\mathrm{Sr}$ derived-solutions were $\approx 3$ times higher than that of $\mathrm{Ca}^{2+}$ in the BBG-Ca derived solution (Figure $3 \mathrm{c}$ ). This data shows that the nature of the substituted cations influences differently their release rate from the BBG network, which might induce distinctive activities to cells. In fact, studies by Mestres et al. ${ }^{38}$
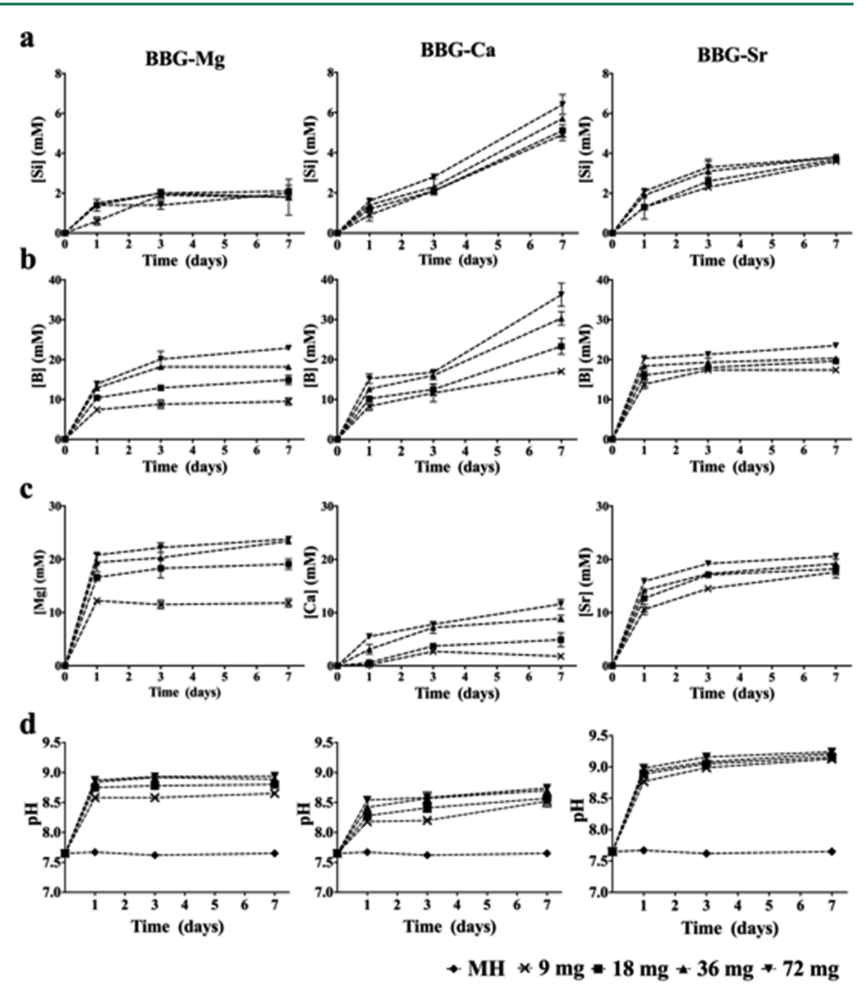

Figure 3. Release of chemical species from the BBGs (BBG-Mg, BBG$\mathrm{Ca}$, and $\mathrm{BBG}-\mathrm{Sr}$ ) into the $\mathrm{MH}$ medium $(\mathrm{a}-\mathrm{c})$ and the corresponding $\mathrm{pH}$ of the solution (d) loaded with different BBG concentrations (9$72 \mathrm{mg} / \mathrm{mL}$ ) after 1,3 , and 7 days of incubation at $37{ }^{\circ} \mathrm{C}$ under agitation. The concentrations were assessed by ICP-AES. The data was obtained from at least three independent samples and is expressed as mean \pm standard deviation $(\mathrm{SD})$.

showed that the high $\mathrm{Mg}$ concentrations in the extracts of $\mathrm{Mg}$ containing cements contribute to their activity against E. coli and $P$. aeruginosa by hyperosmotic stress. On the other hand, the burst release of cations after 1 day led to an increase of $\mathrm{pH}$ $(\approx 1$ unit of $\mathrm{pH}$, Figure $3 \mathrm{~d})$, which might be related with the observed BBGs antibacterial properties. Indeed, Zhang et al., ${ }^{25}$ while studying BGs, correlated mainly the $\mathrm{pH}$ increase in the solution with antibacterial activity. The lower release of $\mathrm{Ca}^{2+}$ into the BBG-Ca solution observed in the present work (Figure $3 c$ ) might explain the lower increase in the solution $\mathrm{pH}$ (Figure $3 \mathrm{~d}$ ), when compared with the dissolution solutions of BBG-Mg and BBG-Sr (e.g., the average of all concentrations for BBG-Mg at day 1 is 8.76 , for BBG-Ca is 8.35 , and for BBG-Sr is 8.90). These results are also consistent with the observed release profiles of $\mathrm{Mg}^{2+}$ and $\mathrm{Sr}^{2+}$ from the respective $\mathrm{BBG}$ compositions over time (generating similar $\mathrm{pH}$ values $\sim 8.8-$ 8.9 in the degradation solutions). These variations in the release kinetics of the divalent cations might influence differently the final BBGs properties, namely their bioactivity and antibacterial capacities. In fact, Allan et al. $^{39}$ reported that degradation of 
Table 2. BBGs (BBG-Mg, BBG-Ca, BBG-Sr) Antibacterial Activity against P. aeruginosa, E. coli, S. aureus, and S. epidermidis as Assessed by the DD Assay at Variable BBG Concentrations $(9-72 \mathrm{mg} / \mathrm{disc})$ during $18 \mathrm{~h}^{a}$

\begin{tabular}{|c|c|c|c|c|c|}
\hline \multirow[b]{2}{*}{ Sample } & \multirow[b]{2}{*}{ Conc (mg/disc) } & \multicolumn{2}{|l|}{ P. aeruginosa } & S. aureus & \multirow{2}{*}{$\frac{\text { S. epidermidis }}{\emptyset \text { zone }[\mathrm{min}-\mathrm{max}](\mathrm{mm})}$} \\
\hline & & $\varnothing$ zone $[\mathrm{min}-\mathrm{max}](\mathrm{mm})$ & $\varnothing$ zone $[\min -\max ](\mathrm{mm})$ & $\varnothing$ zone $[\min -\max ](\mathrm{mm})$ & \\
\hline \multirow[t]{4}{*}{ BBG-Mg } & 9 & 0 & 0 & 0 & $11[0-15]$ \\
\hline & 18 & 0 & 0 & 0 & $12[11-17]$ \\
\hline & 36 & 0 & 0 & 0 & $11[11-18]$ \\
\hline & 72 & 0 & 0 & 0 & $12[10-20]$ \\
\hline \multirow[t]{4}{*}{ BBG-Ca } & 9 & 0 & 0 & 0 & 0 \\
\hline & 18 & 0 & 0 & 0 & 0 \\
\hline & 36 & 0 & 0 & 0 & 0 \\
\hline & 72 & 0 & 0 & 0 & 0 \\
\hline \multirow[t]{4}{*}{ BBG-Sr } & 9 & $17[12-20]$ & 0 & 0 & 0 \\
\hline & 18 & $17[13-21]$ & 0 & 0 & 0 \\
\hline & 36 & $16[14-20]$ & 0 & 0 & 0 \\
\hline & 72 & $18[15-21]$ & 0 & 0 & 0 \\
\hline \multirow{4}{*}{ 45S5 Bioglass } & 9 & 0 & 0 & 0 & $11[0-11]$ \\
\hline & 18 & 0 & 0 & 0 & $14[0-15]$ \\
\hline & 36 & 0 & 0 & 0 & $16[14-19]$ \\
\hline & 72 & $11[0-22]$ & 0 & 0 & $20[18-22]$ \\
\hline
\end{tabular}

${ }^{a_{T}}$ The 45S5 Bioglass was used as a control. The data was obtained from at least three independent experiments and is expressed as the median [min$\max ]$ values of the zones of growth inhibition around each glass agar disc measured in millimeters.

45S5 Bioglass increases the $\mathrm{pH}$, having an antibacterial effect on specific oral bacteria (e.g.: S. sanguis and Porphyromonas gingivalis).

3.3. BBGs' antibacterial properties. The susceptibility of the Gram-negative (P. aeruginosa and E. coli) and Gram-positive (S. aureus and S. epidermidis) bacterial species against variable concentrations of BBGs was initially tested using the DD assay. Table 2 shows the values of the zones of growth inhibition around each BBG-containing disc. The results indicate that 45S5 Bioglass exhibited antibacterial activity against $S$. epidermidis and $P$. aeruginosa, although a high concentration was required to impair the growth of the latest species. Regarding BBGs glasses, BBG-Mg showed antibacterial activity against $S$. epidermidis and BBG-Sr activity against $P$. aeruginosa, independently of the BBG's concentration. In contrast, the BBG-Ca did not present any detrimental effect on the growth of the studied bacterial species.

These promising results lead us to further characterize the antibacterial properties of the developed BBG-Mg and BBG-Sr, including the effect of their dissolution over time by the $\mathrm{BD}$ assay. The BD assay data indicates that BBG-Mg (Figure 4a) prevented the growth of $S$. epidermidis, having a bacteriostatic effect, regardless of the BBG-Mg concentration used and the time of dissolution (activity also observed for the control sample, i.e. 45S5 Bioglass). Surprisingly, the BBG-Sr (Figure 4b), presented bactericidal activity against $P$. aeruginosa for all the tested concentrations, although, at $9 \mathrm{mg} / \mathrm{mL}$, for the first day, a bacteriostatic effect was only observed with $2.6 \log _{10}$ reduction in the initial inoculum. BBG-Sr was able to eradicate $P$. aeruginosa at concentrations $\geq 18 \mathrm{mg} / \mathrm{mL}$ even at the first day of contact. This outperforms 45S5 Bioglass, which only showed bacteriostatic or bactericidal activity at higher concentrations and/or dissolution times against S. epidermidis (Figure 4c) and P. aeruginosa (Figure 4d) [e.g., at the first day of dissolution, BBG-Sr at $18 \mathrm{mg} / \mathrm{mL}$ eradicated $P$. aeruginosa (Figure 4c) while at the same concentration 45S5 Bioglass had a bacteriostatic effect (Figure 4d)]. Other authors also reported bactericidal activity of $45 \mathrm{~S} 5$ Bioglass: Brown et $\mathrm{al}^{40}$ could eradicate $P$. aeruginosa using a concentration of $50 \mathrm{mg} / \mathrm{mL}$ for a a
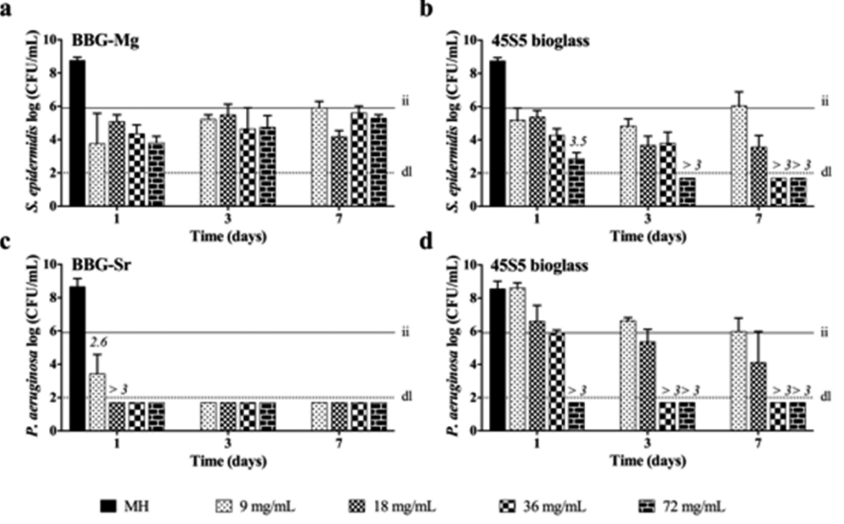

d

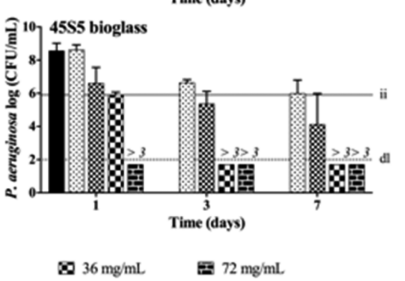

Figure 4. BBG-Mg antibacterial activity against S. epidermidis (a) and of BBG-Sr against $P$. aeruginosa (c). Activity of $45 S 5$ Bioglass against $S$. epidermidis (b) and $P$. aeruginosa $(\mathrm{d})$ used as control, while $\mathrm{MH}$ without BBG was included as a bacterial positive growth control. Bacterial cultures were assessed by the $\mathrm{BD}$ assay after 1,3 , and 7 days of variable concentrations of BBGs $(9-72 \mathrm{mg} / \mathrm{mL})$ dissolution in $\mathrm{MH}$ medium. Each bacterium was diluted to approximately $1 \times 10^{6} \mathrm{CFU}$ in $0.5 \mathrm{~mL}$ of culture medium, added to the different tubes containing known amounts of BBGs dissolved during the specific time frames and incubated at $37^{\circ} \mathrm{C}$ in air for $24 \mathrm{~h}$. The data was obtained from at least three independent samples and is expressed as mean \pm SD. Whenever appropriate, the proportion of the initial inoculum that is rendered incapable of reproduction on subculture is indicated on the top of the bar as the mean $\log _{10}$ reduction. The initial inoculum concentration (ii) and the detection limit ( $\mathrm{dl}$ ) are represented. For bacteria viable counts below the detection limit, one-half of the detection limit is presented $(2 \log \mathrm{CFU} / \mathrm{mL})$.

period of $24 \mathrm{~h}$ incubation under $200 \mathrm{rpm}$ shaking; Hu et al. ${ }^{41}$ also showed $99 \%$ bactericidal activity for concentrations higher than $50 \mathrm{mg} / \mathrm{mL}$ against $S$. epidermidis, among other bacteria. However, to our knowledge, this work describes for the first time BBGs that are able to eradicate bacteria with such a low concentration of glass particles (i.e., $18 \mathrm{mg} / \mathrm{mL}$ ).

Therefore, the $\mathrm{BD}$ assay allowed evaluating the concentration dependence as well as the ability of BBG-Sr to eradicate $P$. 
aeruginosa, as a complement to the DD assay. Thus, BBG-Sr glasses presented relevant antibacterial properties, some of them higher than the ones observed for commercial glasses (e.g., Figure $4 \mathrm{c}$ and $4 \mathrm{~d}$ ). Several authors ${ }^{38,42}$ suggested the influence of increased $\mathrm{pH}$ in the antibacterial activity. As an example, Mestres et al. ${ }^{31}$ showed that magnesium phosphate cements presented antibacterial activity against S. Sanguinis, which was attributed to the alkaline $\mathrm{pH}$. Also, findings from Allan et al. ${ }^{39}$ revealed that supernates from $45 \mathrm{S5}$ Bioglass rapidly increase their $\mathrm{pH}$ to, approximately, 10 . Therefore, the authors suggested that the high $\mathrm{pH}$ alone could be responsible for the observed antibacterial activity. In our case, the $\mathrm{pH}$ variation between BBG-Sr $9 \mathrm{mg} / \mathrm{mL}$ and BBG-Sr $18 \mathrm{mg} / \mathrm{mL}$ at day 1 was not significant (Figure 3d, BBG-Sr), while variations in the antibacterial activity were observed (from bacteriostatic to bactericidal). Furthermore, the same $\mathrm{pH}$ value was recorded for BBG-Mg $72 \mathrm{mg} / \mathrm{mL}$ at day 1 (Figure 3d, BBG-Mg) and it only exhibited bactericidal activity against a different bacterial species (Figure 4). While a high $\mathrm{pH}$ has been associated with the inhibition of bacterial growth, it is noteworthy that $\mathrm{pH}$ might not be the only parameter influencing antibacterial properties. Indeed, the release of specific cations has also been shown to elicit an antibacterial effect. For example, Ohtsu et al. $^{43}$ demonstrated that $\mathrm{Sr}^{2+}$ presents an antibacterial activity against $P$. aeruginosa, through the contact of the bacterium with a strontium borate pigment. In fact, both the release of $\mathrm{Sr}^{2+}$ from the BBG-Sr glass particles and its antibacterial activity toward $P$. aeruginosa are dose dependent (Figure $3 c$ and $4 c$ ). This observation is consistent with the contribution of the released $\mathrm{Sr}^{2+}$ to the antibacterial activity of $\mathrm{BBG}-\mathrm{Sr}^{25,35}$ suggesting that the BBG-Sr's activity toward $P$. aeruginosa may result from a synergist effect of several independent factors (e.g., $\mathrm{Sr}^{2+}$ release, $\mathrm{pH}$ increase, among others).

It is remarkable that in the case of BBG -Sr there is a concentration dependence of the antibacterial activity. Although, the interactions between BBGs and bacteria in in vitro conditions are complex, these data suggest that the incorporation of different substituted cations in the BBGs might be used to tune the antibacterial properties of the glasses.

3.4. In vitro cytotoxic evaluation. In order to be applied as a biomaterial, it is of extreme relevance to study the potential cytotoxic effects of the developed BBGs. A screening of in vitro BBGs cytotoxicity was performed with $\mathrm{SaOs}-2$ cultures.

The MTS assay was used to assess the cell viability of Saos-2 cultured in the presence of BBGs for 7 days (Figure 5). Based on previous works using the Bioglass 45S5 (the control in the present work), the threshold for metabolic activity was set at $50 \% .{ }^{44}$ The BBGs and the commercial control (45S5 Bioglass) showed high cell viability for 3 days of culture. However, after 7 days of culture, a significant reduction in cells viability was observed for BBG-Mg and 45S5 Bioglass for all concentrations. This might be related to the faster release rate of the alkali cation, sodium, from the BBGs, when compared with calcium and strontium. In fact, $45 \mathrm{~S} 5$ Bioglass is composed of a high sodium percentage $(24.5 \%)$. On the other hand, Kansal et al. showed that the increase of the $\mathrm{Na}^{+} / \mathrm{Mg}^{2+}$ ratio causes a decrease in the chemical durability of glasses, which might result in higher release of sodium. ${ }^{45}$ While for BBG-Ca and -Sr glasses only at concentrations higher than $36 \mathrm{mg} / \mathrm{mL}$ was a decay of viability noticed. In general, the three novel BBGs exhibited similar or greater viability than 45S5 Bioglass (e.g., for the concentration of $18 \mathrm{mg} / \mathrm{mL}$, after 3 days of culture, Saos-2
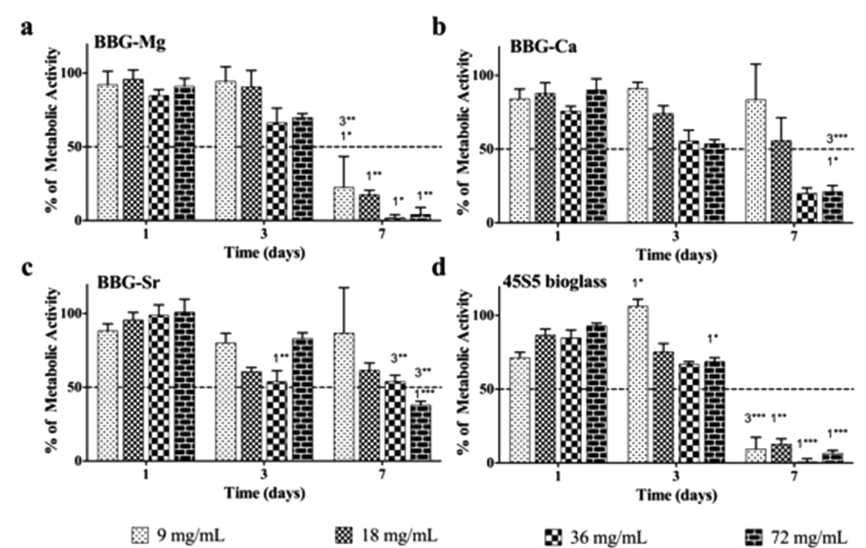

Figure 5. Metabolic activity of SaOs-2 in the presence of BBG-Mg (a), BBG-Ca (b), and BBG-Sr (c) assessed by MTS after 1, 3, and 7 days of variable concentrations of BBGs $(9-72 \mathrm{mg} / \mathrm{mL})$ in the media. The $45 \mathrm{~S} 5$ Bioglass (d) was used as control. Standard culture medium was used as negative control. The data represents the relative metabolic activity (expressed as percentage of the control). The data was obtained from at least three independent samples and is expressed as mean \pm SD. Error bars represent standard deviations. The data was analyzed by nonparametric statistics: Kruskal-Wallis test $(p<0.001)$, followed by a Dunn's Multiple Comparison test. $* * *$ Extremely significant $(p<0.001)$; ** Very significant $(0.001<p<0.01)$; * Significant $(0.01<p<0.05)$. 1 with respect to day $1 ; 3$ with respect to day 3.

viabilities were $90,74,60$, and $66 \%$ for BBG-Mg, $-\mathrm{Ca},-\mathrm{Sr}$, and 45S5 Bioglass, respectively).

Additionally, the cell proliferation profile was assessed by PicoGreen assay for 7 days of culture (Figure 6). The data showed that cell proliferation decreases only after 7 days of culture, reducing the Saos- 2 population to half or less than half the control cell population, corroborating with cell viability data (Figure 5). The reduction of cell viability and proliferation over

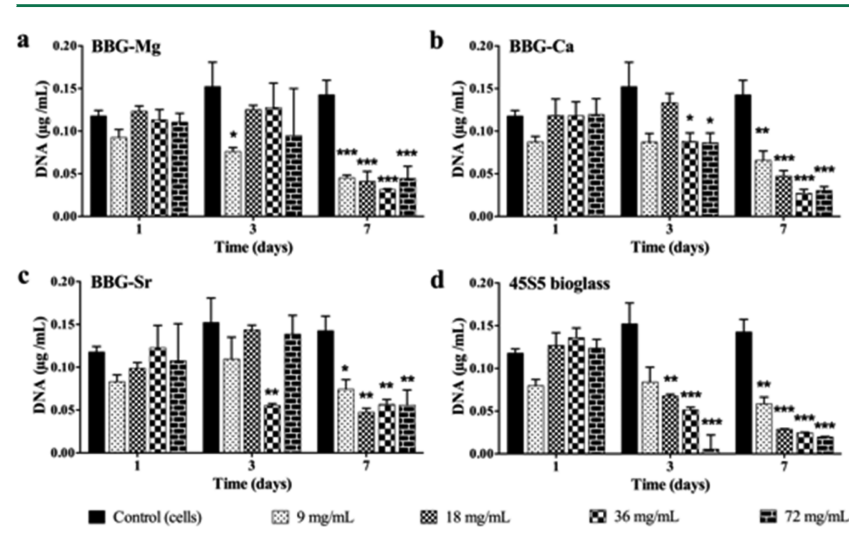

Figure 6. Cell proliferation of SaOs-2 in the presence of BBG-Mg (a), BBG-Ca (b), and BBG-Sr (c) assessed by PicoGreen after 1, 3, and 7 days of variable concentrations of BBGs $(9-72 \mathrm{mg} / \mathrm{mL})$ in the media. The 45S5 Bioglass (d) was used as control. Standard culture medium was used as negative control. The data was obtained from at least three independent samples and is expressed as mean \pm SD. Error bars represent standard deviations. The data was analyzed by nonparametric statistics: Kruskal-Wallis test $(p<0.001)$, followed by a Dunn's Multiple Comparison test. *** Extremely significant $(p<$ $0.001)$; ** Very significant $(0.001<p<0.01)$; * Significant $(0.01<p<$ $0.05)$. The statistical significance of each condition was calculated in relation to the negative control at the respective time point. 
time can be related with the release of cations (e.g., $\mathrm{Mg}^{2+}, \mathrm{Ca}^{2+}$, $\mathrm{Sr}^{2+}$ ) to the culture medium and the resulting increase of $\mathrm{pH}$, which can be deleterious to cells by affecting essential biochemical reactions. ${ }^{46}$ Nevertheless, for a wide range of concentrations, the BBGs showed higher number of cells with respect to the 45S5 Bioglass. Notwithstanding the reduction of cell number and viability over time, there are a wide variety of BBG concentrations that do not present significant cytotoxicity to cells (taken as $50 \%$ of metabolic activity from previous studies with $45 \mathrm{~S} 5$ Bioglass ${ }^{44}$ ). Moreover, BBGs presented lower cytotoxicity than the commercially available $45 \mathrm{S5}$ Bioglass. ${ }^{47}$ Therefore, BBGs can be used to achieve medical-grade materials that couple bone regeneration properties with intrinsic antibacterial activity for the development of biomaterials for bone tissue engineering applications.

The BGs provided a considerable set of new solutions for bone implantation; however, the increase of surgical interventions contributed to the escalation of the incidence of bacterial bone infections. A large number of bone infections cause implant failure and require revision surgery, which causes prolonged hospitalization and occasionally leads to failure of the implants. ${ }^{48}$ Moreover, nowadays, physicians are having difficulties managing bacterial infections, due to the upsurge of drug-resistance bacteria. ${ }^{49}$ Building on the promising results from in vitro tests, BBGs can be used in the development of medical-grade materials with intrinsic antibacterial properties relevant for bone tissue engineering applications.

\section{CONCLUSIONS}

BBGs with different substituted cations $\left(\mathrm{Ca}^{2+}, \mathrm{Sr}^{2+}\right.$, or $\left.\mathrm{Mg}^{2+}\right)$ were successfully fabricated by a melt-quenching technique. In vitro studies revealed that the novel BBGs exhibit bioactive and antibacterial properties relevant for bone tissue engineering applications, with no cytotoxic effects for most of the active concentrations. Specifically, BBG-Ca $(\approx 1.67 \mathrm{Ca} / \mathrm{P}$ ratio $)$ and BBG-Sr $(\approx 1.67 \mathrm{Sr} / \mathrm{P}$ ratio $)$ produced bone-like apatite structures on the surface. BBG-Mg exhibited bacteriostatic activity against $S$. epidermidis, although it did not reach the activity observed for the control sample $45 S 5$ Bioglass. However, BBG-Sr presented bacteriostatic activity against $P$. aeruginosa at a concentration of $9 \mathrm{mg} / \mathrm{mL}$ and was able to eradicate this bacterium at higher concentrations $(\geq 18 \mathrm{mg}$ / $\mathrm{mL}$ ). Finally, this study demonstrated that BBGs can be used as relevant biomaterials that present different characteristics appropriate for bone tissue engineering applications: providing bone integration properties (BBG-Ca); antibacterial capacity (BBG-Mg); or even coupled properties (BBG-Sr).

\section{AUTHOR INFORMATION}

\section{Corresponding Authors}

*(Ricardo A. Pires) E-mail: rpires@dep.uminho.pt. Tel: +351 253510 907. Fax: +351253510909.

*(João S. Fernandes) E-mail: joao.fernandes@dep.uminho.pt. Tel: +351253510 900. Fax: +351253510909.

\section{Notes}

The authors declare no competing financial interest.

\section{ACKNOWLEDGMENTS}

The authors gratefully acknowledge financial support from Portuguese Foundation for Science and Technology (Ph.D. grant $\mathrm{BD} / 73162 / 2010$ to JSF); European Union's Seventh Framework Programme (FP7/2007-2013) under Grant No.
REGPOT-CT2012-31633-POLARIS to RAP and MM; and QREN project (RL3 - TEC1 - NORTE-01-0124-FEDER000020) cofinanced by North Portugal Regional Operational Programme (ON.2 - O Novo Norte), under the NSRF, through the ERDF (to MM); and the European Research Council under grant agreement ERC-2012-ADG-20120216321266 for the project ComplexiTE.

\section{REFERENCES}

(1) Hench, L. The story of Bioglass. J. Mater. Sci.: Mater. Med. 2006, 17 (11), 967-978.

(2) Fu, H.; Rahaman, M.; Day, D.; Huang, W. Long-term conversion of $45 \mathrm{~S} 5$ bioactive glass-ceramic microspheres in aqueous phosphate solution. J. Mater. Sci.: Mater. Med. 2012, 23 (5), 1181-1191.

(3) Xu, S.; Yang, X.; Chen, X.; Shao, H.; He, Y.; Zhang, L.; Yang, G.; Gou, Z. Effect of borosilicate glass on the mechanical and biodegradation properties of 45S5-derived bioactive glass-ceramics. J. Non-Cryst. Solids 2014, 405, 91-99.

(4) Axford, J. S. Joint and bone infections. Medicine 2010, 38 (4), 194-201.

(5) Vassena, C.; Fenu, S.; Giuliani, F.; Fantetti, L.; Roncucci, G.; Simonutti, G.; Romanò, C. L.; De Francesco, R.; Drago, L. Photodynamic antibacterial and antibiofilm activity of RLP068/Cl against Staphylococcus aureus and Pseudomonas aeruginosa forming biofilms on prosthetic material. Int. J. Antimicrob. Agents 2014, 44 (1), $47-55$.

(6) Simchi, A.; Tamjid, E.; Pishbin, F.; Boccaccini, A. R. Recent progress in inorganic and composite coatings with bactericidal capability for orthopaedic applications. Nanomedicine 2011, 7 (1), 22-39.

(7) Malizos, K. N.; Gougoulias, N. E.; Dailiana, Z. H.; Varitimidis, S.; Bargiotas, K. A.; Paridis, D. Ankle and foot osteomyelitis: Treatment protocol and clinical results. Injury 2010, 41 (3), 285-293.

(8) Rahaman, M. N.; Liang, W.; Day, D. E. Preparation and Bioactive Characteristics of Porous Borate Glass Substrates. In Advances in Bioceramics and Biocomposites: Ceramic Engineering and Science Proceedings; John Wiley \& Sons, Inc.: 2008; pp 1-10. DOI: 10.1002/9780470291269.ch1.

(9) Pan, H. B.; Zhao, X. L.; Zhang, X.; Zhang, K. B.; Li, L. C.; Li, Z. Y.; Lam, W. M.; Lu, W. W.; Wang, D. P.; Huang, W. H.; Lin, K. L.; Chang, J. Strontium borate glass: potential biomaterial for bone regeneration. J. R. Soc., Interface 2010, 7 (48), 1025-1031.

(10) Lakhkar, N. J.; Lee, I.-H.; Kim, H.-W.; Salih, V.; Wall, I. B.; Knowles, J. C. Bone formation controlled by biologically relevant inorganic ions: Role and controlled delivery from phosphate-based glasses. Adv. Drug Delivery Rev. 2013, 65 (4), 405-420.

(11) Hoppe, A.; Güldal, N. S.; Boccaccini, A. R. A review of the biological response to ionic dissolution products from bioactive glasses and glass-ceramics. Biomaterials 2011, 32 (11), 2757-2774.

(12) Jones, J. R. Review of bioactive glass: From Hench to hybrids. Acta Biomater. 2013, 9 (1), 4457-4486.

(13) Rahaman, M. N. Bioactive ceramics and glasses for tissue engineering. In Tissue Engineering Using Ceramics and Polymers, 2nd ed.; Boccaccini, A. R., Ma, P. X., Eds.; Woodhead Publishing: 2014; Chapter 3, pp 67-114. DOI: http://dx.doi.org/10.1533/ 9780857097163.1.67.

(14) Chapin, R.; Ku, W.; Kenney, M.; McCoy, H. The effects of dietary boric acid on bone strength in rats. Biol. Trace Elem. Res. 1998, $66(1-3), 395-399$.

(15) Yamasaki, Y.; Yoshida, Y.; Okazaki, M.; Shimazu, A.; Uchida, T.; Kubo, T.; Akagawa, Y.; Hamada, Y.; Takahashi, J.; Matsuura, N. Synthesis of functionally graded $\mathrm{MgCO} 3$ apatite accelerating osteoblast adhesion. J. Biomed. Mater. Res. 2002, 62 (1), 99-105.

(16) Zreiqat, H.; Howlett, C. R.; Zannettino, A.; Evans, P.; SchulzeTanzil, G.; Knabe, C.; Shakibaei, M. Mechanisms of magnesiumstimulated adhesion of osteoblastic cells to commonly used orthopaedic implants. J. Biomed. Mater. Res. 2002, 62 (2), 175-184. 
(17) Maeno, S.; Niki, Y.; Matsumoto, H.; Morioka, H.; Yatabe, T.; Funayama, A.; Toyama, Y.; Taguchi, T.; Tanaka, J. The effect of calcium ion concentration on osteoblast viability, proliferation and differentiation in monolayer and 3D culture. Biomaterials 2005, 26 (23), 4847-4855

(18) Marie, P. J.; Ammann, P.; Boivin, G.; Rey, C. Mechanisms of Action and Therapeutic Potential of Strontium in Bone. Calcif. Tissue Int. 2001, 69 (3), 121-129.

(19) Marie, P. J. Strontium ranelate: A physiological approach for optimizing bone formation and resorption. Bone 2006, 38 (2, Supplement 1), 10-14.

(20) Wu, C.; Fan, W.; Gelinsky, M.; Xiao, Y.; Simon, P.; Schulze, R.; Doert, T.; Luo, Y.; Cuniberti, G. Bioactive $\mathrm{SrO}-\mathrm{SiO} 2$ glass with wellordered mesopores: Characterization, physiochemistry and biological properties. Acta Biomater. 2011, 7 (4), 1797-1806.

(21) Jones, J.; Ehrenfried, L.; Saravanapavan, P.; Hench, L. Controlling ion release from bioactive glass foam scaffolds with antibacterial properties. J. Mater. Sci.: Mater. Med. 2006, 17 (11), 989996.

(22) Palza, H.; Escobar, B.; Bejarano, J.; Bravo, D.; Diaz-Dosque, M.; Perez, J. Designing antimicrobial bioactive glass materials with embedded metal ions synthesized by the sol-gel method. Mater. Sci. Eng., C 2013, 33 (7), 3795-3801.

(23) Goh, Y.-F.; Alshemary, A. Z.; Akram, M.; Abdul Kadir, M. R.; Hussain, R. In-vitro characterization of antibacterial bioactive glass containing ceria. Ceram. Int. 2014, 40 (1, Part A), 729-737.

(24) Ren, L.; Lin, X.; Tan, L.; Yang, K. Effect of surface coating on antibacterial behavior of magnesium based metals. Mater. Lett. 2011, 65 (23-24), 3509-3511.

(25) Zhang, L.; Tan, P. Y.; Chow, C. L.; Lim, C. K.; Tan, O. K.; Tse, M. S.; Sze, C. C. Antibacterial activities of mechanochemically synthesized perovskite strontium titanate ferrite metal oxide. Colloids Surf., A 2014, 456 (0), 169-175.

(26) Lin, Y.; Yang, Z.; Cheng, J.; Wang, L. Synthesis, characterization and antibacterial property of strontium half and totally substituted hydroxyapatite nanoparticles. J. Wuhan Univ. Technol., Mater. Sci. Ed. 2008, 23 (4), 475-479.

(27) Kokubo, T.; Takadama, H. How useful is SBF in predicting in vivo bone bioactivity? Biomaterials 2006, 27 (15), 2907-2915.

(28) Matuschek, E.; Brown, D. F. J.; Kahlmeter, G. Development of the EUCAST disk diffusion antimicrobial susceptibility testing method and its implementation in routine microbiology laboratories. Clin. Microbiol. Infect. 2014, 20 (4), O255-O266.

(29) European Committee for Antimicrobial Susceptibility Testing of the European Society of Clinical, M.; Infectious, D.. Determination of minimum inhibitory concentrations (MICs) of antibacterial agents by broth dilution. Clin. Microbiol. Infect. 2003, 9 (8), ix-xv.

(30) Tchouaffi-Nana, F.; Ballard, T. E.; Cary, C. H.; Macdonald, T. L.; Sifri, C. D.; Hoffman, P. S. Nitazoxanide Inhibits Biofilm Formation by Staphylococcus epidermidis by Blocking Accumulation on Surfaces. Antimicrob. Agents Chemother. 2010, 54 (7), 2767-2774. (31) European Committee for Antimicrobial Susceptibility Testing of the European Society of Clinical, M.; Infectious, D.. Terminology relating to methods for the determination of susceptibility of bacteria to antimicrobial agents. Clin. Microbiol. Infect. 2000, 6 (9), 503-508.

(32) Salimi, M. H.; Heughebaert, J. C.; Nancollas, G. H. Crystal growth of calcium phosphates in the presence of magnesium ions. Langmuir 1985, 1 (1), 119-122.

(33) Wang, H.; Lee, J.-K.; Moursi, A.; Lannutti, J. J. Ca/P ratio effects on the degradation of hydroxyapatite in vitro. J. Biomed. Mater. Res. 2003, 67A (2), 599-608.

(34) Fredholm, Y. C.; Karpukhina, N.; Brauer, D. S.; Jones, J. R.; Law, R. V.; Hill, R. G. Influence of strontium for calcium substitution in bioactive glasses on degradation, ion release and apatite formation. $J$. R. Soc., Interface 2012, 9 (70), 880-889.

(35) Ravi, N. D.; Balu, R.; Sampath Kumar, T. S. StrontiumSubstituted Calcium Deficient Hydroxyapatite Nanoparticles: Synthesis, Characterization, and Antibacterial Properties. J. Am. Ceram. Soc. 2012, 95 (9), 2700-2708.
(36) Hench, L. L. Bioceramics. J. Am. Ceram. Soc. 1998, 81 (7), 1705-1728

(37) Ohtsuki, C.; Kushitani, H.; Kokubo, T.; Kotani, S.; Yamamuro, $\mathrm{T}$. Apatite formation on the surface of ceravital-type glass-ceramic in the body. J. Biomed. Mater. Res. 1991, 25 (11), 1363-1370.

(38) Mestres, G.; Abdolhosseini, M.; Bowles, W.; Huang, S. H.; Aparicio, C.; Gorr, S. U.; Ginebra, M. P. Antimicrobial properties and dentin bonding strength of magnesium phosphate cements. Acta Biomater. 2013, 9 (9), 8384-8393.

(39) Allan, I.; Newman, H.; Wilson, M. Antibacterial activity of particulate Bioglass ${ }^{\circledR}$ against supra- and subgingival bacteria. Biomaterials 2001, 22 (12), 1683-1687.

(40) Brown, L.; Darmoc, M.; Havener, M.; Clineff, T.; Ins, O.; Malven, P. Antibacterial Effects od 45S5 Bioactive Glass against Four Clnicaly Relevant Bacterial Species. 55"' Annual Meeting of the Orthopedic Research Society, Las Vegas, NV, 2009.

(41) Hu, S.; Chang, J.; Liu, M.; Ning, C. Study on antibacterial effect of 45S5 Bioglass®. J. Mater. Sci.: Mater. Med. 2009, 20 (1), 281-286.

(42) Leung, Y. H.; Ng, A. M. C.; Xu, X.; Shen, Z.; Gethings, L. A.; Wong, M. T.; Chan, C. M. N.; Guo, M. Y.; Ng, Y. H.; Djurišíć, A. B.; Lee, P. K. H.; Chan, W. K.; Yu, L. H.; Phillips, D. L.; Ma, A. P. Y.; Leung, F. C. C. Mechanisms of Antibacterial Activity of MgO: NonROS Mediated Toxicity of $\mathrm{MgO}$ Nanoparticles Towards Escherichia coli. Small 2014, 10, n/a-n/a.

(43) Ohtsu, K.; Yoshida, H.; Akamatsu, N. Strontium borate pigment composition, method of making same, and processes for imparting anti-corrosive, anti-bacterial and/or anti-fungal, and non-flammable properties to materials by using same. 1995, EP0648818 A1.

(44) Rismanchian, M.; Khodaeian, N.; Bahramian, L.; Fathi, M.; Sadeghi-Aliabadi, H. In-vitro Comparison of Cytotoxicity of Two Bioactive Glasses in Micropowder and Nanopowder forms. Iranian Journal of Pharmaceutical Research: IJPR 2013, 12 (3), 437-443.

(45) Kansal, I.; Reddy, A.; Muñoz, F.; Choi, S.-J.; Kim, H.-W.; Tulyaganov, D. U.; Ferreira, J. M. F. Structure, biodegradation behavior and cytotoxicity of alkali-containing alkaline-earth phosphosilicate glasses. Mater. Sci. Eng., C 2014, 44, 159-165.

(46) Teo, A.; Mantalaris, A.; Lim, M. Influence of culture $\mathrm{pH}$ on proliferation and cardiac differentiation of murine embryonic stem cells. Biochem. Eng. J. 2014, 90 (0), 8-15.

(47) Krishnan, V.; Lakshmi, T. Bioglass: A novel biocompatible innovation. Journal of Advanced Pharmaceutical Technology \& Research 2013, Apr-Jun (4(2)), 78-83. DOI: 10.4103/2231-4040.111523.

(48) Miola, M.; Bruno, M.; Maina, G.; Fucale, G.; Lucchetta, G.; Vernè, E. Antibiotic-free composite bone cements with antibacterial and bioactive properties. A preliminary study. Mater. Sci. Eng., C 2014, $43(0), 65-75$.

(49) Zhao, X. Antibacterial bioactive materials. In Bioactive Materials in Medicine; Zhao, X., Courtney, J. M., Qian, H., Eds.; Woodhead Publishing: 2011; Chapter 5, pp 97-123. ISBN: 9781845696245. 